\title{
Determinants of neonatal near miss among neonates delivered in public hospitals in Shashemane city administration, Ethiopia, 2021 Facility based unmatched case control study
}

Henok Girma Guda ( $\sim$ gudahenok@gmail.com )

Meda Wulabu University

Research Article

Keywords: Neonatal near miss, Neonate, Shashemene

Posted Date: January 28th, 2022

DOI: https://doi.org/10.21203/rs.3.rs-1307379/v1

License: (c) (i) This work is licensed under a Creative Commons Attribution 4.0 International License. Read Full License 


\section{Abstract}

Background: Neonatal near miss is an event that nearly died between 0-28 days but survived by chance or good quality of care. The number of neonates who survived morbidities were approximately 5 times greater than those died. However, there is limited evidence that state the determinants of neonatal near miss in Ethiopia and particularly in Shashemane. So, this study attempted to identify determinants of Neonatal near miss among neonate delivered in public Hospitals in Shashemene, Oromia, Ethiopia.

Methods: Facility based unmatched case-control study conducted from March, 22, 2021 to May 22, 2021. Structured and pretested questionnaires used for data collection. 104 cases were selected consecutively and 208 controls were selected by systematic random sampling by $2^{\text {nd }} k$ during study period. For each near-miss case, two controls were selected. After data collection, data were checked for consistency, coded and entered by using EPI INFO 7 and exported to statistical package for social science for analysis by using binary logistic regression on the basis Odds ratio, $95 \% \mathrm{Cl}$ and $p$-value of less than 0.05 . Variables with $p<0.25$ in Bivariable analysis entered into a multivariable logistic regression model using the backward variable selection method.

Result: The result show that mother age group between 20-34 had 0.12 less odds to experience neonatal near miss than age group below 20 years old. [AOR=0.12, 95\%(Cl=0.02-0.76)]. Neonates who were delivered by spontaneous vaginal delivery had 0.38 less odds of experiencing neonatal near miss than neonates delivered by instrumental assisted delivery and Cesarean section [AOR 0.38, 95\% ( $\mathrm{Cl}=0.22-0.68)$ ]. Delivery followed by partograph had 0.25 less odds likely to develop neonatal near miss than those not followed by partograph [AOR=0.25 95\% $(\mathrm{Cl}, 0.11-0.54)]$.

Conclusion: Age of mother, gestational age, delivery mode and delivery followed by partograph were determinants of the neonatal near miss. So, women conceive at below 20 years of old, mother that will not give birth by spontaneous vaginal delivery should be advised of the greater risk of neonatal near miss. Health worker in delivery ward should use partograph for every delivery in both hospitals.

\section{Introduction}

Neonatal Near Miss (NNM) is an evolving concept and so far, there is no a standard definition for NNM. However, it may be referred to newborns who had a severe morbidity but survived this condition within the first 28 days of life [3]. The Latin American Center of Perinatology (CLAP, Montevideo, Uruguay) from the Pan America Health Organization develop definition of the Neonatal Near Miss as "any newborn infant who exhibited pragmatic and/or management criteria and survived the first 28 days of life" using WHO global survey conducted 2005 and WHO multi-country survey in 2014 [4].

Neonatal near miss concept and the criteria based on clinical audit have been proposed as useful approach for obtaining useful information on maternal and newborn health [3]. Neonatal near miss definition and criteria may be seen as a basis for future applications of the near-miss concept in neonatal health. These tools can be used to inform policy makers on how to apply scarce resources for improving the quality of care and reducing neonatal mortality [5]. 
By the end of 2030 Sustainable Development Goal (SDG) global target is an NMR of 12 deaths per 1000 Livebirths and if the slow reduction continues newborn deaths account for 45 percent of under-five deaths globally, up from 40 percent in 1990[6]. And following the launch of the Global strategy for women's, children and adolescent health (2016-2030), WHO developed a vision for quality of care in new born health services which sees a future in which "every newborn receives quality care throughout pregnancy, childbirth and postnatal period" [7].

Ministry of Health $(\mathrm{MOH})$ of Ethiopia is working with WHO and other partners to strengthen and invest in care particularly around the time of birth and the first week where most newborns are dying in this time period and also focus on improving the quality of newborn care from pregnancy to entire postnatal period [8]. And implemented the Health Sector Development Program and Health Sector Transformation Plan (HSTP) that helped reform the nation's health system in the last 20 years. The HSTP has identified quality and equity as a cornerstone of the transformation agenda focusing mainly on maternal, neonatal and child health; nutrition and others [9].

Since, the Neonatal Near Miss is new concept; there is dearth of literature that indicate determinants factors. In Ethiopia also there is dearth literature that identify determinants of NNM. Despite, Neonatal health related problem still there that is justified by 2019 Biannual report of Shashemane comprehensive specialized hospital (SCSH) from total 1573 Livebirth delivered in the Hospital 445 Newborns admit to NICU with at least with one indication and from admitted 29 Neonate died and in Melka Oda general hospital report from 2569 Livebirth 320 newborn admit to NICU and 24 newborns died. And particular there is no study done on it in Shashemane city. So, this study attempted to identify determinant for NNM in this study area, used as part of evidence, basis framework for another researcher, public hospitals and city administration health office.

Study done by WHO in WHOMCS and WHOGS in 2005 put great insight to NNM approach with its own limitation of the study design which is survey type and does not identify basic determinants of NNM [3]. And study in Brazil classify NNM based only on organ-dysfunction markers it doesn't account pragmatic criteria and has limitation of representativeness since it's done in 17 Health facilities which are selected purposely [5]. The study in three Africa country does not consider the differences in sociodemographic characteristic of study area and which survey type study design. All study in Ethiopia take assumption to calculate sample size from study done in Brazil which has different sociodemographic and other characteristics and it does not incorporate some of the variables such as Health worker that attend delivery and partograph follow during attending labor $[10,20,21]$.

As stated above, Neonatal health problem are still major public issue throughout the globe and in Ethiopia and there is scarcity of evidence that identify determinants factors of NNM in a globe and in Ethiopia. NNM approach is important to intervene on Neonatal Health. But the available study has some limitation like methodological difference, use only pragmatic criteria, representativeness, weak study design, doesn't incorporate important variable and stated different determinants across the setting. So, this study attempted to identify determinants of NNM in this study area by facility-based case control study design, by considering the above-mentioned limitation of available literature and by adding some important factor like Partograph usage and deliver attended by. 


\section{Material And Methods}

Study Area and Study period.

Shashemene city administration is found in Oromia Region, $240 \mathrm{~km}$ from capital Addis Ababa to South. This study conducted in two public hospitals in Shashemene city in Melka Oda general hospital and Shashemene comprehensive specialized hospital/SCSH/ from March 22, 2021 to May 22, 2021. An Institution based unmatched case-control study design was conducted.

\section{Source population}

All Livebirth neonates delivered in public hospital in Shashemane city administration were used as Source population and study population for case were all livebirth neonates delivered and admitted at NICU in hospitals and for controls were all livebirths' neonates delivered and diagnosed as healthy baby in hospitals.

\section{Inclusion and Exclusion criteria}

\section{Inclusion criteria}

Cases (Neonatal Near Miss) were livebirth delivered and admitted to NICU of public hospitals in Shashemene city.

Control were neonates delivered and admitted to postnatal or neonatal ward

Exclusion criteria home delivered baby, multiple pregnancies, neonates referred from other health care institutions,

Sample size determination techniques.

The sample size was calculated using Epi Info 7 software, confidence level of $95 \%$, power of the study, $80 \%$, the case- control ratio 1:2. Expected percent of exposures in control 11.7\%, and percent exposure among cases $25.7 \%$. It is calculated using a study done in Hawassa. Pregnancy Induced HTN as one of the main exposure variable for neonatal near-miss that provide the maximum sample size of 312 with $10 \%$ nonresponse rate [10]. By adding the non-response rate sample size will be 104 cases and 208 controls.

\section{Operational Definition}

Neonatal near miss/NNM/ is considered when the newborn faced at least one of the following proposed criteria but survived those complications [5].

Pragmatic criteria; Birth weight $<1750 \mathrm{~g}$, Gestational age $<33$ weeks, 5th-minute Apgar score $<7$ Management criteria; Mechanical ventilation, Cardiopulmonary resuscitation (CPR), Intubation, Nasal continuous positive airway pressure (NCPAP), Parenteral antibiotics, use of parenteral nutrition, Vasoactive drugs, Phototherapy during the first 28 days, Anticonvulsants, use of blood products, use of steroids for the treatment of refractory hypoglycemia, Surgical procedures, Use antenatal steroid [4]. 
The neonatal period - refers the day of birth up to 28 days of life [8].

APGAR scoring The APGAR score is now used worldwide to quickly assess the health of an infant one minute and five minutes after birth. The 1-minute APGAR score measures how well the newborn tolerated the birthing process. The 5-minute APGAR score assesses how well the newborn is adapting to the environment [11].

\section{Newborn death}

The death within 28 days of birth of any live-born baby regardless of weight or gestational age [12].

Data quality control and data collection tools.

The questionnaire was pretested in Dodola general hospital which have almost similar characteristic with this study area prior to the actual data collection period on $5 \%$ of actual sample. Primary data; sociodemographic and economic characteristics of mothers were collected through face-to-face-interview and secondary data; obstetrics and medical history of mothers and neonatal characteristics were extracted from maternal and neonate medical.

Method of data analysis.

After data collection data checked for consistency, coded and entered by using EPI INFO 7 and export to SPSS version 25 for analysis. Bivariate binary logistic regression carried out to identify determinants of Neonatal Near Miss on the basis of $\mathrm{OR}, 95 \% \mathrm{Cl}$ and $\mathrm{p}$-value of less than 0.05 . Variables with $\mathrm{p}<0.25$ in Bivariate binary logistic regression analysis entered into a Multivariate binary logistic regression model using the Backward LR. During Multivariate binary logistic regression analysis model fitness will be check by Hosmer-Lemeshow model fitness. Variance inflation factors (VIFs) and Tolerance used to check Multicollinearity among independent variables. A VIF below 10 and Tolerance above 0.1 was checked and SPSS output show absence of Multicollinearity.

\section{Results}

Socio-demographic characteristics.

In this study 104 cases and 208 controls were involved with a null nonresponse rate for both cases and controls, as it was a case-control study. The mean age in years and a standard deviation of neonate's mother was $26.85 \pm 7.17$ for cases and $27.58 \pm 4.46$ for controls. Mothers of newborn were under age of 20 among case were $28(26.9 \%)$ and only $12(5.8 \%)$ among controls were under age of 20 . Out of neonates mother $104(50 \%)$ in cases and 61(58.7\%) in control groups were Muslim religion.

Eighty-three (79.8\%) ethnicity group among cases and 130(62.5\%) control were Oromo. Educational status of neonate mother among cases in primary education were $51(49 \%)$ and among control $77(37 \%)$. Regarding education of father, $76(36.5 \%)$ of neonates' fathers had the educational status of secondary among cases 
and $21(20.9 \%)$ for controls. Housewife maternal occupation for maternal among cases were $74(71.2 \%)$ and for control were $119(23.1 \%)$ [Table 1].

Table1: Sociodemographic characteristic of respondent from March 22, 2021 to May 22, 2021 in Melka Oda General Hospital and SCRH in Shashemene, Ethiopia 


\begin{tabular}{|c|c|c|c|c|}
\hline Variables & Category & $\begin{array}{l}\text { Case N } \\
(\%)\end{array}$ & $\begin{array}{l}\text { Control N } \\
(\%)\end{array}$ & Total N (\%) \\
\hline \multirow[t]{3}{*}{ Age of mother } & $<20$ & $28(26.9)$ & $12(5.8)$ & $40(12.8)$ \\
\hline & $20-34$ & $53(51)$ & $178(85.6)$ & $231(68.26)$ \\
\hline & $>34$ & $23(22.1)$ & $18(8.7)$ & $41(13.14)$ \\
\hline \multirow[t]{2}{*}{ Place of Residence } & Urban & $45(43.3)$ & $98(47.1)$ & $143(45.8)$ \\
\hline & Rural & $59(56.7)$ & $110(52.9)$ & $169(54.1)$ \\
\hline \multirow[t]{5}{*}{ Religion } & Muslim & $104(50)$ & $61(58.7)$ & $165(52.8)$ \\
\hline & Orthodox & $60(28.8)$ & $20(19.2)$ & $80(25.6)$ \\
\hline & Protestant & $30(14.4)$ & $15(14.4)$ & $45(14.4)$ \\
\hline & Catholic & $13(6.3)$ & $7(6.7)$ & $20(6.4)$ \\
\hline & Wakefata & $1(0.5)$ & $1(1)$ & $2(0.6)$ \\
\hline \multirow[t]{6}{*}{ Ethnicity } & Oromo & $83(79.8)$ & $130(62.5)$ & $130(41.6)$ \\
\hline & Amhara & $12(11.5)$ & $34(16.3)$ & $56(17.9)$ \\
\hline & Wolaita & $4(3.8)$ & $9(4.3)$ & $13(4.1)$ \\
\hline & Tigre & $0(0)$ & $8(3.8)$ & $8(2.5)$ \\
\hline & Gurage & $1(1)$ & $12(5.8)$ & $13(4.1)$ \\
\hline & Silte & $3(2.88)$ & $15(7.2)$ & $17(5.4)$ \\
\hline \multirow[t]{2}{*}{ Admission mode of Mother } & Self-referred & $60(57.7)$ & $121(58.2)$ & $181(58.1)$ \\
\hline & Referred from another facility & $44(42.3)$ & $87(41.8)$ & $131(41.9)$ \\
\hline \multirow{3}{*}{$\begin{array}{l}\text { Means of transport to } \\
\text { Hospital }\end{array}$} & Ambulance & $48(46.2)$ & $86(41.3)$ & $134(42.9)$ \\
\hline & Public transport & $52(50)$ & $104(50)$ & $156(50)$ \\
\hline & $\begin{array}{l}\text { Personnel Vehicles and By } \\
\text { walking }\end{array}$ & $4(3.8)$ & 18(8.6) & 22(7.05) \\
\hline \multirow{4}{*}{$\begin{array}{l}\text { Educational level of the } \\
\text { mother }\end{array}$} & No formal education & $28(26.9)$ & $26(12.5)$ & $54(17.3)$ \\
\hline & Primary (1-8) & $51(49)$ & $77(37)$ & $128(33.6)$ \\
\hline & Secondary (9-12) & $22(21.2)$ & $86(41.3)$ & 108(34.6) \\
\hline & Collage and above & $3(2.9)$ & 19(9.1) & $22(7.05)$ \\
\hline $\begin{array}{l}\text { Educational level of the } \\
\text { Parental }\end{array}$ & No formal education & $14(6.7)$ & $21(20.2)$ & $35(11.2)$ \\
\hline
\end{tabular}




\begin{tabular}{|lllll|}
\hline Variables & Category & $\begin{array}{l}\text { Case N } \\
(\%)\end{array}$ & $\begin{array}{l}\text { Control N } \\
(\%)\end{array}$ & Total N (\%) \\
\hline & Primary (1-8) & $46(22.1)$ & $33(31.7)$ & $79(25.3)$ \\
\hline & Secondary (9-12) & $76(36.5)$ & $21(20.2)$ & $97(31.1)$ \\
\hline & Collage and above & $72(34.6)$ & $29(27.9)$ & $101(32.3)$ \\
\hline Occupation of the mother & House Wife & $74(71.2)$ & $119(23.1)$ & $193(61.8)$ \\
\hline & Merchant & $21(20.2)$ & $41(19.7)$ & $62(19.8)$ \\
\hline Gamily Size & Government or NGO Employee & $8(7.7)$ & $48(23.1)$ & $56(17.9)$ \\
\hline & Daily Laborer & $1(1)$ & $0(0)$ & $1(0.0)$ \\
\hline & $<4$ & $69(66.3)$ & $119(57.2)$ & $188(60.2)$ \\
\hline $4-7$ & $18(17.1)$ & $75(36.1)$ & $93(29.8)$ \\
\hline & $>=7$ & $17(16.3)$ & $14(6.7)$ & \\
\hline
\end{tabular}

\section{Obstetric factors and newborn condition}

Ninety-nine (95.2\%) of neonate mother received at least one ANC visit among cases group and 205(98.6\%) in control. Regarding Number of ANC visit during current pregnancy, 32(30.8\%) of neonates' mother in cases and $175(84.1 \%)$ in control had at least 4 visits.

Out of the total number of neonates' mothers, $49(47.1 \%)$ of cases and $81(38.9 \%)$ of controls were primipara. Birth interval between current and previous pregnancy in multipara mother those with less than 24 months were $38(66.6 \%)$ among cases and among control 18(13.5\%) were became pregnant with in less than 24 months [Table 2]. 
Table 2

Obstetrics and neonatal related characteristics of neonatal near miss among neonates admitted from March 22, 2021 to May 28, 2021 in Melka Oda General Hospital and SCRH in Shashemane, Ethiopia

\begin{tabular}{|c|c|c|c|c|}
\hline Variables & Category & $\begin{array}{l}\text { Case N } \\
\text { (\%) }\end{array}$ & $\begin{array}{l}\text { Control N } \\
\text { (\%) }\end{array}$ & $\begin{array}{l}\text { Total N } \\
\text { (\%) }\end{array}$ \\
\hline \multirow[t]{2}{*}{ Parity } & Primipara & $49(47.1)$ & $81(38.9)$ & $130(41.6)$ \\
\hline & Multipara & $55(52.9)$ & $127(61.1)$ & $182(58.3)$ \\
\hline \multirow[t]{2}{*}{ Birth Interval for Multi } & $<24$ & $38(66.6)$ & 18(13.5) & $56(30.4)$ \\
\hline & $>=24$ & 13(13.5) & 115(53.3) & $128(69.5)$ \\
\hline \multirow[t]{3}{*}{ Gestational age at Birth } & $<37$ & $34(33.6)$ & $17(8.1)$ & $51(16.3)$ \\
\hline & $37-41$ & $59(56.7)$ & $170(81.7)$ & $229(73.4)$ \\
\hline & $>41$ & 11(10.5) & $10(4.8)$ & $21(6.7)$ \\
\hline \multirow{2}{*}{$\begin{array}{l}\text { At least one ANC during current } \\
\text { pregnancy }\end{array}$} & Yes & $99(95.2)$ & 205(98.60) & $304(97.4)$ \\
\hline & No & $5(4.8)$ & $3(1.4)$ & $8(2.5)$ \\
\hline \multirow[t]{2}{*}{ Number of ANC 1st visit } & $<4$ visits & $72(69.2)$ & $33(15.9)$ & 105(33.6) \\
\hline & $>=4$ visits & $32(30.8)$ & $175(84.1)$ & $207(66.3)$ \\
\hline \multirow{3}{*}{$\begin{array}{l}\text { Maternal preexisting condition } \\
\text { Hypertension }\end{array}$} & No History & 197(94.7) & $98(94.2)$ & $295(94.5)$ \\
\hline & & & & \\
\hline & Has history of & $9(8.6)$ & $6(2.8)$ & $15(4.8)$ \\
\hline \multirow[t]{2}{*}{ Presentation } & Cephalic & $98(94.2)$ & 194(93.3) & 292(93.5) \\
\hline & $\begin{array}{l}\text { Breech } \\
\text { Transverse/Face/Brow }\end{array}$ & $6(5.7)$ & $14(6.7)$ & $20(6.4)$ \\
\hline \multirow[t]{2}{*}{ Delivery Mode } & $\begin{array}{l}\text { Instrumental assisted } \\
\text { delivery \& CS }\end{array}$ & $45(43.2)$ & $65(31.2)$ & $110(35.2)$ \\
\hline & SVD & $59(56.7)$ & $143(68.8)$ & $110(35.2)$ \\
\hline \multirow[t]{3}{*}{ Delivery Attended by } & $\begin{array}{l}\text { Obstetrician and } \\
\text { Gynecologist }\end{array}$ & 10(9.6) & 19(9.1) & $29(9.2)$ \\
\hline & IESO & $33(31.7)$ & $60(28.8)$ & $93(29.8)$ \\
\hline & Midwife & $61(58.7)$ & $129(62)$ & $190(60.8)$ \\
\hline \multirow[t]{2}{*}{ Sex of Neonate } & Male & $49(47.1)$ & $115(55.3)$ & $164(52.5)$ \\
\hline & Female & $55(52.9)$ & $93(44.7)$ & $148(47.4)$ \\
\hline \multirow[t]{2}{*}{ Follow by partograph } & No & $23(22.1)$ & 19(9.1) & $42(13.4)$ \\
\hline & Yes & 81(77.8) & 189(90.8) & $270(86.5)$ \\
\hline
\end{tabular}




\begin{tabular}{|lllll|}
\hline Variables & Category & $\begin{array}{l}\text { Case N } \\
(\%)\end{array}$ & $\begin{array}{l}\text { Control N } \\
(\%)\end{array}$ & $\begin{array}{l}\text { Total N } \\
\text { (\%) }\end{array}$ \\
\hline Maternal complication Dystocia & No complication & $191(91.8)$ & $58(55.8)$ & $249(79.8)$ \\
\cline { 2 - 5 } & Cephalopelvic Disproportion & $1(0.5)$ & $14(13.5)$ & $15(4.8)$ \\
\hline & Prolonged labor & $15(7.2)$ & $26(25)$ & $41(13.1)$ \\
\hline Neonate's weight (in mg) & Uterine prerupture & $1(0.5)$ & $6(5.8)$ & $7(2.2)$ \\
\hline & $<2500$ & $30(28.8)$ & $25(12)$ & $55(17.6)$ \\
\hline & $2500-4000$ & $72(69.2)$ & $179(86.1)$ & $251(80.4)$ \\
\hline & $>4000$ & $2(1.9)$ & $4(1.9)$ & $6(1.9)$ \\
\hline
\end{tabular}

\section{Determinants of neonatal near miss}

Neonate's mother age group aged between 20-34 age years old were 0.12 less likely to experience NNM when compared to those aged less than 20 years old [AOR=0.12,95\%, $\mathrm{Cl}=0.02-0.76]$.

Neonate's mother give birth in GA of 37-41 weeks were 0.16 less likely to experiencing neonatal near miss than neonates of $<37$ weeks of gestational age at birth [AOR=0.16, 95\% Cl: $(0.06-0.47)$ ]. Neonate's mother who was give birth by SVD were 0.38 times less odds of experiencing neonatal near miss than neonates gave birth by IAD and CS [AOR=0.38, $\mathrm{Cl}, 95 \%(0.22-0.68)]$. Delivery followed by partograph were 0.25 less likely to develop neonatal near miss than those not followed by partograph [AOR=0.25 $\mathrm{Cl} ; 95 \%(0.11-0.54)]$ [Table 3]. 
Table 3

Bivariable and multivariable analysis of factors associated with neonatal near miss among neonates delivered and admitted $(n=312)$ to from March 22, 2021 to May 22, 2021 in Melka Oda General Hospital and SCRH in Shashemene, Ethiopia

\begin{tabular}{|c|c|c|c|c|c|}
\hline \multirow[t]{3}{*}{ Variables $(n=312)$} & \multirow[t]{3}{*}{ Category } & \multicolumn{2}{|l|}{ NNM } & \multirow[t]{3}{*}{$\begin{array}{l}\text { COR } \\
(95 \% \mathrm{Cl})\end{array}$} & \multirow[t]{3}{*}{$\begin{array}{l}\text { AOR } \\
(95 \% \mathrm{Cl})\end{array}$} \\
\hline & & Case & Control & & \\
\hline & & $\mathrm{N} \%$ & $\mathrm{~N} \%$ & & \\
\hline \multirow[t]{3}{*}{ Age of mother } & $<20$ & $28(26.9)$ & $12(5.8)$ & 1 & 1 \\
\hline & $20-34$ & $53(51)$ & 178(85.6) & $\begin{array}{l}0.13(0.06- \\
0.26)^{*}\end{array}$ & $\begin{array}{l}0.12(0.02- \\
0.76) \star \star\end{array}$ \\
\hline & $>34$ & $23(22.1)$ & $18(8.7)$ & $\begin{array}{l}0.54(0.21- \\
1.36)\end{array}$ & $\begin{array}{l}0.56(0.081- \\
3.87)\end{array}$ \\
\hline \multirow{4}{*}{$\begin{array}{l}\text { Educational level of } \\
\text { the mother }\end{array}$} & No formal education & $51(49)$ & $77(37)$ & 1 & \\
\hline & Primary (1-8) & $22(21.2)$ & $86(41.3)$ & $\begin{array}{l}0.38(0.16- \\
2.78)\end{array}$ & $\begin{array}{l}0.24(0.10- \\
1.96)\end{array}$ \\
\hline & Secondary (9-12) & $3(2.9)$ & $19(9.1)$ & $\begin{array}{l}0.24(0.16- \\
2.46)\end{array}$ & $\begin{array}{l}0.18(0.14- \\
2.01)\end{array}$ \\
\hline & Collage and above & $28(26.9)$ & $26(12.5)$ & $\begin{array}{l}1.62(1.34- \\
5.01)\end{array}$ & $\begin{array}{l}1.09(0.52- \\
2.25)\end{array}$ \\
\hline \multirow[t]{2}{*}{ Parity } & Primipara & $49(47.1)$ & $81(38.9)$ & 1 & 1 \\
\hline & Multipara & $55(52.9)$ & 127(61.1) & $\begin{array}{l}0.71(0.66- \\
2.24)\end{array}$ & $\begin{array}{l}0.68(0.40- \\
3.17)\end{array}$ \\
\hline \multirow{2}{*}{$\begin{array}{l}\text { At least one ANC } \\
\text { during current } \\
\text { pregnancy }\end{array}$} & Yes & $99(95.2)$ & $205(98.60)$ & 1 & 1 \\
\hline & No & $5(4.8)$ & $3(1.4)$ & $\begin{array}{l}3.45(0.80- \\
14.73)\end{array}$ & $\begin{array}{l}1.39(0.17- \\
11.01)\end{array}$ \\
\hline \multirow{3}{*}{$\begin{array}{l}\text { Gestational age at } \\
\text { Birth }\end{array}$} & $<37$ & $34(33.6)$ & $17(8.1)$ & 1 & 1 \\
\hline & $37-41$ & $59(56.7)$ & $170(81.7)$ & $\begin{array}{l}0.17(0.14- \\
0.43) *\end{array}$ & $\begin{array}{l}0.16(0.06- \\
0.47) \star \star\end{array}$ \\
\hline & $>41$ & $11(10.5)$ & $10(4.8)$ & $\begin{array}{l}0.55(0.04- \\
11.5)\end{array}$ & $\begin{array}{l}0.02(0.001- \\
0.64)\end{array}$ \\
\hline \multirow[t]{2}{*}{ Presentation } & Cephalic & $98(94.2)$ & 194(93.3) & 1 & 1 \\
\hline & $\begin{array}{l}\text { Breech } \\
\text { Transverse/Face/Brow }\end{array}$ & $6(5.7)$ & $14(6.7)$ & $\begin{array}{l}0.84(0.34- \\
3.78)\end{array}$ & $\begin{array}{l}1.06(0.15- \\
7.12)\end{array}$ \\
\hline
\end{tabular}

**Significant at $p$ - value of $\leq 0.05$ 


\begin{tabular}{|c|c|c|c|c|c|}
\hline Variables $(n=312)$ & Category & NNM & & $\begin{array}{l}\text { COR } \\
(95 \% \mathrm{Cl})\end{array}$ & $\begin{array}{l}\text { AOR } \\
(95 \% \mathrm{Cl})\end{array}$ \\
\hline \multirow[t]{2}{*}{ Delivery Mode } & $\begin{array}{l}\text { Instrumental assisted } \\
\text { delivery \& CS }\end{array}$ & $45(43.2)$ & $65(31.2)$ & 1 & 1 \\
\hline & SVD & $59(56.7)$ & $143(68.8)$ & $\begin{array}{l}0.59(0.36- \\
0.96)^{*}\end{array}$ & $\begin{array}{l}0.38(0.22- \\
0.68) \star *\end{array}$ \\
\hline \multirow[t]{2}{*}{ Follow by partograph } & No & $23(22.1)$ & $19(9.1)$ & 1 & 1 \\
\hline & Yes & $81(77.8)$ & 189(90.8) & $\begin{array}{l}0.35(0.18- \\
0.68) *\end{array}$ & $\begin{array}{l}0.25(0.11- \\
0.54) \star *\end{array}$ \\
\hline
\end{tabular}

Finally, Age of mother, gestational age between 37-41 weeks, SVD and delivery followed by partograph were identified as determinants of the neonatal near miss.

\section{Discussion}

The result from multivariable shows that age of mother between 20-34, gestational age 37-41 weeks, SVD and delivery followed by partograph were identified as determinants of the neonatal near miss.

Age of mother between 20-34 had lower odds of experiencing Neonatal Near Miss than those mothers of age below 20 years old. This result is in line with study done in Tigray that showed that being under 18 years of age at first marriage [AOR=2.8,95\%Cl:1.18-6.83], had higher odds of experience NNM than above age of 18[14]. This is because at early age physiological and psychological they aren't enough matured and early pregnancy in prematurity stage associated with neonatal near miss. Additionally, as most of the respondents were from the rural area and uneducated, there is still early marriage in the area.

In study done in Brazil show that advanced maternal age ( $>35$ years old) was to be a risk factor for neonatal near miss in nulliparous $(\mathrm{OR}=1.62 ; 95 \% \mathrm{Cl}$ : $1.05-2.50)$ and multiparous women $(\mathrm{OR}=1.51 ; 95 \% \mathrm{Cl}: 1.20-1.91)$ when compared to women 20-29 years of age [15]. There were also in study done in northeast Brazil Infants born to older mothers showed a nearly 2-fold risk of neonatal near miss, compared to mothers aged 20 to 34 (OR: 0.43; 95\% Cl: 0.23-0.83) [16]. But studies done in Brazil use different age group category with a range of 10 years when compared with current study.

Other variables which significantly associate with NNM was GA. GA with 37-41 weeks had 0.16 times lower odds of experiencing neonatal near miss than neonates of $<37$ weeks of gestational age at birth $[A O R=0.16$, $95 \% \mathrm{Cl}:(0.06-0.47)]$. In line with this result, study in Ghana the most predictive elements of the NNM were gestational age $>33$ weeks. [17], study in Brazil gestational age $<33$ weeks was identified in $85.7 \%$ of hospitalized newborns, and this was the factor that most contributed to the near miss rate [18]. Also, a study conducted in Brazil, shows that $>80 \%$ near miss case were $<30$ weeks of gestational age [16]. this is because most complication has supposed to be related with prematurity. In Ethiopia also study conducted in Ambo show that the gestational age between $36-41$ weeks were protected against neonatal near miss than 
neonates of $\geq 42$ weeks of gestational age at birth [AOR=0.13, 95\% Cl:(0.051, 0.32)].[21] this is because prematurity impose the newborn for life threating condition because of his immature organ.

Opposite to result, in study done in three African country (Benin, Burkina Faso and Morocco) most neonatal near misses occurred in babies without extreme values of gestational age (>41) [19]. This result show opposite with current study it's because methodological difference, study setting and use large sample size than current study.

Another variable which is determinates of NNM were mode of delivery study show that neonate SVD had less odds of experiencing NNM than delivered assisted instrumentally and CS. This result shows the similar conclusion with study done in Ambo which reveal that neonates who were given birth by instrumental delivery had higher odds of experiencing neonatal near miss than neonates gave birth by spontaneous vaginal delivery $[\mathrm{AOR}=4.62,95 \% \mathrm{Cl}$ : $(1.78,11.98)][21]$. It is supposed to be a fact that instrumental delivery can cause a lot of adverse effect on neonates and mothers and increase risk of such complications is estimated to lead to NNM. Other study in Gamo Gofa show that mother who gave birth by cesarean mode of delivery were 4.89 times more likely to have NNM cases than SVD and Instrumental assisted delivery [20]. And also in other ways, evidence from Brazil stated that neonatal near miss rate was higher among babies delivered by $\mathrm{C} / \mathrm{S}$ than in those delivered through SVD. The result shows the same result with current result.

Another variable, delivery followed by partograph had less odds of developing Neonatal near miss than not followed by partograph. Even though there was no study support this finding, it is a fact that delivery not followed by partograph can lead to a lot of adverse effect on neonates and mothers. To avoid adverse outcome a chart called a partograph will help you to follow the progress of a labor that is prolonged and which may be obstructed. It will also alert you to signs of fetal distress. The partograph has been established as the "gold standard" labor monitoring tool universally. It has recommended by the World Health Organization (WHO) for use in active labor [8].

In this study Occupation of mother and parental, marital status, complication during labor and delivery, parity, delivery attended health worker, and presentation were insignificantly associated with neonatal near miss. And also, ethnicity, religion, sex of neonate, place of the residence had also not significate association with neonatal near-miss cases in this finding. This is because, nowadays there is an improvement in the health care delivery system, advances in technology, and seeking health information irrespective of residence, Ethnicity, religion and educational status.

Finally, the strength of this study was employing a standardized neonatal near miss identification criteria to avoid misclassification and the incomplete questionnaires were filled to got $100 \%$ response rate of the respondents. This study didn't analysis selection criteria for case event, the criteria only to identify the neonatal near miss event and identify additional determinant factor (Partograph usage) that isn't addressed yet in published literature.

\section{Limitation}


In this study, data corresponding to sociodemographic and economic variables were collected by interviews and might be subject to recall bias. The readers should consider the limitations of this study while interpreting the finding and the other scholars will do more to overcome those limitations.

\section{Conclusion}

Age of mother, gestational age, delivery mode and delivery followed by partograph were determinants of the neonatal near miss in public hospitals in Shashemene, Oromia. And other researchers should do further investigation about NNM event.

\section{Abbreviations}

APGAR: $\quad$ Appearance, Pulse, Grimace, Activity, Respiration

$\mathrm{Cl}$ Confidence Interval

COVID 19: $\quad$ Corona Virus Disease 19

CLAP: $\quad$ Centro Latino-Americano de Perinatology

CPAP: $\quad$ Continuous Positive Airways Pressure

CPD: $\quad$ Cephalo Pelvic Disproportion

CS: $\quad$ Caesarean Section

EDHS: $\quad$ Ethiopia Demographic Health Survey

$\mathrm{FMOH} ; \quad \quad \quad$ Federal Ministry of Health

GA: Gestational Age

HSTP: $\quad$ Health Sector Transformation Plan

ICU: Intensive Care Unit

NNM: $\quad$ Neonatal Near Miss

SCSRH; Shashemene Comprehensive Specialized Referral Hospital

SDG: $\quad$ Sustainable Development Goal

SVD: $\quad$ Spontaneous Vaginal Delivery

WHO: $\quad$ World Health Organization

WHOGS World Health Organization Global Survey 
WHOMCS World Health Organization Multi-Country Survey

\section{Declarations}

\section{Competing Interests}

All authors have no competing interests, Henok Girma, Bikila Lenca, Lalisa Gedefa, Ephrem Girma, Sintayehu Gabisa, Bonso Ami declare that they have no competing interests.

\section{Declaration}

\section{Ethical Consideration and consent to participate}

Ethical clearance was obtained from the institutional review board of school of public health Madda Walabu University. It was confirmed that the study met the ethical and scientific standards outlined in national and international guidelines.

\section{Authors' contributions}

HG wrote the draft proposal, participated in data collection and analyzed the data. BL, LK, EG, SG and BA approved the proposal with major revisions, participated in data analysis and revised subsequent drafts of the paper. All authors read and approved the final manuscript.

\section{Funding}

No fund was obtained for this research.

\section{Consent for publication}

Not applicable

\section{Availability of data and materials}

The datasets used and analysed during the current study are available from the corresponding author on reasonable request.

\section{Acknowledgment}

We are grateful to Meda Wulabu University, Shashemane campus for approval of the ethical clearance and technical comments. And also, our gratitude also goes to Shashemene comprehensive specialized hospital/SCSH/, Melka Oda general hospital and all study participants for their commitment in responding to our interviews.

\section{References}

1. Pileggi, C. et al. (2010) 'Neonatal near miss approach in the 2005 WHO Global Survey Brazil', 86(1), pp. 21-26. doi: 10.2223/JPED.1965. 
2. Say, L. (2010) 'Neonatal near miss: A potentially useful approach to assess quality of newborn care', Jornal de Pediatria, 86(1), pp. 1-2. doi: 10.2223/JPED.1978.

3. Surve, S. (2017) 'Neonatal near miss review: Tracking its conceptual evolution and way', 21(2), pp. 264271.

4. Cecatti, G. et al. (2015) 'Neonatal Near Miss: the need for a standard definition and appropriate criteria and the rationale for a prospective surveillance system', 2015(12), pp. 820-826. doi: 10.6061/clinics/2015(12)10.

5. Mussi-pinhata, M. M., Cecatti, J. G. and Mori, R. (2014) 'Development of criteria for identifying neonatal near-miss cases: analysis of two WHO multicountry cross-sectional studies', pp. 110-118. doi: 10.1111/1471-0528.12637.

6. WHO and UNICEF (2017) 'REACHING THE EVERY NEWBORN NATIONAL 2020 MILESTONES COUNTRY PROGRESS, PLANS AND MOVING FORWARD. http://apps.who.int/iris/bitstream/10665/25

7. Health, C. and Quality, C. (2019) 'Ethiopian Health Care Quality Bulletin Ethiopian Health Care Quality Bulletin', 1 (May).

8. Amil, B. et al. (2020) WORLD HEALTH 2020, Journal of Chemical Information and Modeling. Available at:

https://doi.org/10.1016/j.tmaid.2020.101607\%0Ahttps://doi.org/10.1016/j.ijsu.2020.02.034\%0Ahttps:// onlinelibrary.wiley.com/doi/abs/10.1111/cjag.12228\%0Ahttps://doi.org/10.1016/j.ssci.2020.104773\%0 Ahttps://doi.org/10.1016/j.jinf.2020.04.011\%0Ahttps://doi.o.

9. Ethiopian Health Sector Transformation Plan.2015/16 - 2019/20 (2015) 'Ethiopian Health Sector Transformation Plan.2015/16 - 2019/20', Federal Democratic Republic of Ethiopia Ministry of Health, 20(May), p. 50.

10. Anteneh, T. (2019) 'Neonatal Near Misses and Associated Factors Among Mother' s Who Give a Live Neonate at Hawassa City Governmental Hospitals, 2019. A Facility Based Cross-Sectional Study Design'.

11. Franck, L. et al. (2014) 'Recommended standards for newborn ICU design', (March). doi: $10.1038 /$ s.jp.7211587.

12. Strategy, C. H. (2011) 'NEWBORN'.

13. World Health Organisation (2014) 'Every Newborn Action Plan', Who, p. 58.

14. Nugussie F, Alemayehu M, M. K. (2018) 'A Case-Control Study Examining Determinants of Neonatal Near-Miss in Public Hospitals in Tigray Region, Northern Ethiopia _ Nugussie _ Research \& Reviews_ Journal of Medical Science and Technology'.

15. Martinelli, K. G. and Pacheco, V. E. (2019) 'Advanced maternal age and factors associated with neonatal near miss in nulliparous and multiparous women Idade materna avançada e fatores associados com o near miss neonatal em mulheres nulíparas e multíparas Edad avanzada en la maternidad y factores aso', 35(12). doi: 10.1590/0102-311X00222218.

16. Kale, P. L. et al. (2017) 'Neonatal near miss Six public maternity hospitals in South East Brazil', Cadernos de Saude Publica, 33(4), pp. 1-12. doi: 10.1590/0102-311X00179115. 
17. Bakari, A. et al. (2019) 'Neonatal near-misses in Ghana: A prospective, observational, multi-center study', BMC Pediatrics, 19(1), pp. 1-10. doi: 10.1186/s12887-019-1883-y.

18. Maia, M. R. G. et al. (2020) 'Neonatal near miss in the intensive care unit', Revista brasileira de enfermagem, 73(6), p. e20180931. doi: 10.1590/0034-7167-2018-0931.

19. Ronsmans, C. et al. (2016) 'Characteristics of neonatal near miss in hospitals in Benin, Burkina Faso and Morocco in 2012 - 2013', 21(4), pp. 535-545. doi: 10.1111/tmi.12682.

20. Mersha, A., Bante, A. and Shibiru, S. (2019) 'Factors associated with neonatal near-miss in selected hospitals of Gamo and Gofa zones, southern Ethiopia : nested case- control study', pp. 1-8.

21. Roga, E. Y., kassa, N. A. and Bacha, Y. D. (2019a) 'Determinants of Neonatal Near Miss Among Neonates Admitted to Ambo University Referral Hospital and Ambo General Hospital, Ethiopia, 2019', pp. 1-20. doi: 10.21203/rs.2.13935/v1.

22. Santos, Juliana P, Pileggi-castro, C., Jr, J. S. C., Silva, A. A., Duran, P. and Serruya, S. J. (2015) 'Neonatal near miss: a systematic review', BMC Pregnancy and Childbirth, (December). doi: 10.1186/s12884-0150758-y.

23. Status, C. (2019) 'Neonatal Near Miss and its associated factors at Injibara General Hospital, Awi Zone, Northwest Ethiopia, 2019', pp. 1-14. doi: 10.21203/rs.2.12536/v1.

24. Tassew, H. A., Kassie, F. Y. and Mihret, M. S. (2020) 'Neonatal near Miss and Its Predictors among Neonates Delivered at Debretabor General Hospital, Northern Ethiopia ; A Retrospective Analysis', 2020(Mlic).

25. Tekelab, T. et al. (2020) 'Incidence and determinants of neonatal near miss in south Ethiopia: A prospective cohort study', BMC Pregnancy and Childbirth, 20(1), pp. 1-13. doi: 10.1186/s12884-02003049-w.

26. 5719/1/9789241512619-eng.pdf?ua=1 ', (May 2017), pp. 2015-2018. 